\title{
Disposições afetivas no romance Le fou d'Omar, de Abla Farhoud.
}

\author{
Affective dispositions in Abla Farhoud's Le fou d'Omar
}

Dionei Mathias ${ }^{1}$

Submetido em 5 de novembro e provado em 15 de dezembro de 2019.

Resumo: Publicado em 2005, Le fou d'Omar é um romance escrito por Abla Farhoud, escritora canadense de origem libanesa. Narrado a partir de diversas perspectivas, o romance trata de conflitos de família, mas também das dificuldades inerentes ao processo de assentamento no novo contexto cultural do Quebec. Nessa interseção, os afetos se revelam como centrais para a compreensão da dinâmica de vozes e, sobretudo, do acesso à produção discursiva. Afetos, neste contexto, são entendidos como modos de manutenção ou interrupção de relações sociais, incluindo a administração de pertencimento e exclusão. No processo de socialização, o indivíduo aprender a lidar com essas dinâmicas a fim de participar do conjunto de vozes que definem a imaginação das formatações de grupo. $\mathrm{O}$ romance de Abla Farhoud representa essas dinâmicas afetivas e mostra como elas são responsáveis pela tomada de consciência da imposição de diferença e sua transmissão. Nesse sentido, este artigo deseja discutir disposições afetivas em dois situações: no microcosmo da família, incluindo relações de amizade e no macrocosmo social de contextos nacionais e internacionais.

Palavras-chave: Abla Farhoud. Le fou d'Omar. Diferença. Afetos. Fluxos migratórios.

Abstract: Published in 2005, Le fou d'Omar is a novel written by Abla Farhoud, Canadian writer of Lebanese origin. Narrated from different perspectives, the novel deals with family conflicts, but also with difficulties inherent to the process of settling down in the new cultural context of Quebec. In this intersection, affects turn out to be pivotal in understanding the dynamics of voices and, above all, in understanding the access to discursive production. Affects, in this context, are understood as modes of maintainting or interupting social relations, including the administration of belonging and exclusion. In socialization processes, individuals learn to cope with these dynamics, in order to participate in the body of voices which define the imagination of group formation. Farhoud's novel represents these affective dynamics e shows how they are responsible for becoming aware of the imposition of difference and its transmission. In this sense, this article wishes to discuss affective dispositions in two situations: in the microcosm of family including friendships and in the social macrocosm of national and international contexts.

Keywords: Abla Farhoud. Le fou d'Omar. Difference. Affects. Migratory flows. 


\section{Introdução}

Num dos estudos mais importantes sobre a literatura dos fluxos migratórios, Clément Moisan e Renate Hildebrand (2001) retraçam em Ces étrangers du dedans a história da literatura migrante no Quebec, identificando quatro fases que caracterizam essas vozes migrantes: uni, pluri, inter e transcultural. O que está no centro dessa configuração discursiva é o conceito de cultura, com suas técnicas de simbolização da realidade. De certo modo, o que diferencia cada uma das fases identificadas pelos estudiosos é a narrativa cultural, com suas regras específicas de apropriação e representação de realidade, e adotada pelos diferentes atores sociais que compõem esse espaço de interação social. A administração da matriz de sentidos e suas lógicas de afiliação, portanto, servem como princípio de categorização dessas diferentes vozes migrantes.

Ao delinear esse caminho do percurso histórico da literatura oriunda de fluxos migratórios, Moisan e Hildebrand oscilam entre dois polos: por um lado, questionam implicitamente a narrativa de uma literatura quebequense originária, da qual participam somente aqueles que foram socializados naquele espaço cultural e que dialogam com a tessitura cultural daquelas coordenadas geográficas, portanto mantendo um elo da tradição. Por outro lado, eles inovam essa narrativa ao indicar a presença de vozes cuja primeira socialização, em muitos casos, ocorreu em outro contexto cultural e, ao se inscreverem na literatura quebequense, a inovam com percepções que criam novas malhas culturais, produzindo até certo ponto uma ruptura. Assim, entre tradição e ruptura, eles abandonam a grande narrativa literária nacional estabelecida para instaurar outra, agora com a presença de vozes migrantes.

Dumontet (2008, p. 88), por sua vez, recupera esse conflito em volta do processo de legitimação das vozes e da organização do produção discursiva, sugerindo, em seu estudo, quatro vetores para caracterizar essa escrita e seu lugar de fala no contexto da literatura quebequense: a desterritorialização da fala migrante, a ressemantização do espaço, a escrita em várias línguas e a escrita em fragmentos (DUMONTET, 2008, p. 93 $)^{2}$. Semelhantemente ao movimento de Moisan e Hildebrand, o ponto de partida parece residir no modo como malhas culturais são organizadas e na estratégias de simbolização da experiência cultural desses atores sociais. Em ambos os casos, a diferença cultural e a 
necessidade de apropriação da gramática cultural que rege as interações daquele espaço representam o ponto de partida para a reorganização discursiva em volta da literatura de fluxos migratórios. Em ambos os casos, há um esforço de reconstruir a memória cultural daquele espaço, a partir de vozes discursivamente periféricas, a fim de construir um crivo de transmissão dessa outra herança cultural.

Em ambos os estudos, parece haver um movimento de estabilização imagéticodiscursiva de grupos minoritários. Embora ambos problematizem e questionem essa formatação, a instauração desse vetor discursivo também contribui para sua fixação. Para evitar essa forma indireta de essencialização, Donna Bennett (2005, p. 9) sugere o termo "polybridity"para evitar os binarismos e as inúmeras hifenações que caracterizam a grande narrativa nacional, enfatizando que a "a literatura das nossas culturas nos oferece outras formas de enxergar" (BENNETT, 2005, p. 12)3. Para essa compreensão, também contribuem os importantes estudos de Simon Harel (2005, p. 38-39) que caracteriza essa nova escrita como "elogio à desterritorialização" (“éloge de la déterritorialisation") e como forma de "lutar contra o arraigamento" ("lutter contre l'enracinement"). Ambos os estudiosos, pensam a literatura como plataforma que pensa e discute uma nova forma de imaginar a nação, não mais em termos de inclusão e exclusão, mas a partir de uma lógica mais complexa que se encontra no cerne da gênese cultural.

Isso também vale para os estudos de Pierre Ouellet, estes mais interessados na gênese de memórias que contribuem para a formação das narrativas de representação. Como Bennett e Harel, Ouellet se interessa menos em recuperar e fixar discursos de fundação com suas lógicas de inclusão e exclusão para tentar compreender como novos vetores da memória surgem a partir de uma realidade rizomática com fragmentos diversos de experiências e pertencimentos múltiplos. A partir do convívio e das interações cotidianas surgem "comunidades da memória" (OUELLET, 2012), pautadas por sentidos compartilhados e pelo poder da palavra no processo de comunicação e formação de discursos. Como afirma Bernd (2017, p. 135) ao discutir as contribuições de Harel e Ouellet, "eles não caem na armadilha do pensamento binário que necessariamente implica exclusões, na medida em que o binarismo impede a percepção de um terceiro caminho"4. Abandonando os binarismos e ideando novas formas de captar realidades, a literatura 
contribui para a imaginação dessas "comunidades de memória", especialmente por encenar percursos afetivos que permitem vislumbrar ou refazer experiências sensíveis.

O romance Le fou d'Omar de Abla Farhoud se inscreve nessa configuração discursiva, ao representar uma família de imigrantes libaneses no Quebec. Nele, a autora, filha de pais que emigraram do Líbano, representa no universo ficcional os conflitos de assentamento nesse novo espaço cultural, problematizando questões de alteridade, pertencimento, língua e reconfiguração de identidade. Nesse esforço, o trabalho de Abla Farhoud cria uma confluência com os interesses dos críticos literários que buscam compreender as dinâmicas das malhas culturais na literatura quebequense. Ao mesmo tempo, contudo, seu romance também chama atenção para um outro vetor importante nessa interseção, o qual reside nas malhas afetivas, que de certo modo precedem as práticas de simbolização cultural.

Com efeito, antes de participar de um campo discursivo e constituir uma voz própria com o objetivo de rever as grandes narrativas que representam uma comunidade imaginada (ANDERSON, 2008), há uma dinâmica afetiva que, em grande parte, decide até que ponto uma tessitura cultural se torna ou não alvo de problematização ou digna de transmissão. São os afetos que criam marcas no universo pessoal, impelindo-o a deixar rastros de experiências, por meio da simbolização. São afetos que levam grupos a alimentar o desejo de representar alguns elementos de uma comunidade, enquanto outros permanecem como voz ausente. Esquecimento, denegação ou rejeição de um herança cultural resultam também de dinâmicas afetivas.

Para Frijda (1987, p. 71), emoções são "tendências de estabelecer, manter ou romper uma relação com o meio"s. Com isso, o início da gênese de sentido e sua posterior prática cultural de simbolização sempre contêm uma coloração afetiva, pois o trabalho cognitivo intelectual pressupõe um interesse por parte do indivíduo envolvido em representar um evento da realidade vivida, a fim de compartilhá-lo com os membros das comunidades com que interage. Portanto, práticas de rememoração ou da construção de uma voz para comunidades marcadas pelo silenciamento implica uma disposição afetiva, produzida a partir das formatações discursivas pré-existentes. 
Num viés construtivista, essa situação fica ainda mais complexa, pois se assume que emoções são frutos de uma socialização cultural:

Para a maioria dos sociólogos, emoções são socialmente construídas no sentido de que o que a pessoa sente está condicionado pela socialização numa cultura e pela participação em estruturas sociais. Ideologias culturais, crenças e normas, na medida em que impactam em estruturas sociais, definem quais emoções devem ser sentidas e como essas emoções culturalmente definidas devem ser expressadas. Emoções, desse modo, são construções sociais (TURNER/STETS, 2005, p. 2$)^{6}$.

Com isso, todo indivíduo que passa por um processo de socialização cultural também passa por uma espécie de treinamento afetivo que lhe ensina o que deve sentir e como deve expressar suas emoções. Isso, contudo, não pode significar que toda emoção seja produto unicamente de uma configuração cultural. Por um lado, a cultura dominante de um espaço geográfico certamente oferece uma gama de roteiros afetivos, os quais acabam sendo adotados pela grande maioria dessa comunidade cultural. Por outro, no entanto, ainda há uma infinidade de experiências afetivas pessoais que remetem ao universo individual do sujeito. Afetividade - além da base biológica que não discutimos aqui - parece oscilar entre esses dois polos.

Para o contexto de imigração, isso tem algumas implicações específicas. Atores sociais oriundos de contextos de fluxos migratórios passam por um processo de ressocialização cultural, ao optar pelo assentamento em outra comunidade cultural. Nesse processo, também precisam aprender as novas formas de codificar e roteirizar emoções, a fim de ter êxito em suas metas existenciais. Ao mesmo tempo, trazem seus modelos afetivos adquiridos na cultura de origem, os quais, em grande parte, permanecem inconscientes em suas ações. Com isso, além dos conflitos que surgem naturalmente entre indivíduos no processo de negociação afetiva, ainda incidem as diferenças da socialização.

Nesse sentido, este artigo deseja discutir a representação da afetividade no romance Le fou d'Omar, em dois níveis: por um lado, o microcosmo da experiência social como estrangeiro, por outro, dimensões do macrocosmo com suas modalidades de interação. O ponto de partida está na tese de que dinâmicas afetivas precedem formatações discursivas que dão voz às experiências da migração. Assim, "os estrangeiros de dentro" 
ou "a poética da escrita migrante" surgem a partir de vetores afetivos rizomáticos existentes num espaço cultural.

O romance Le fou d'Omar é narrado a partir de quatro perspectivas diferentes: Lucien Laflamme (o vizinho quebequense), Rawi Omar (um dos filhos de Omar Khaled e que mais tarde troca o nome para Pierre Luc Duranceau), Omar Khaled (o pai, que vive com o filho Radwan e que falece) e, por fim, Radwan Omar (o filho mais velho, com problemas psiquiátricos). A alternância dos pontos de vista se revela como estratégia importante para a criação de um panorama afetivo que revela a condição de estrangeiro no Quebec, mas que também expõe os conflitos familiares, desencadeados pelos distúrbios psiquiátricos de Radwan Omar. Na confluência de experiências dessas quatro vozes, surgem as malhas afetivas que vão caracterizar as existências representadas no universo diegético.

O título, por fim, parece aludir a uma condição patológica, embora permaneça ambíguo. De qual Omar o título fala não fica terminantemente esclarecido. Tampouco fica esclarecido a que loucura o título se refere. A temática dos transtornos psiquiátricos não é rara em obras ficcionais do contexto de fluxos migratórios, especialmente quando a narrativa trata de experiências bélicas, como é o exemplo também do canadense Rawi Hage, no romance Cockroach. Com efeito, muitos escritores de origem libanesa tiveram que deixar o país, por conta de conflitos armados e retratam essas experiências traumáticas em seus textos. O romance de Abla Farhoud também traz sedimentos desses traumas, mas não se limita a isso. Ele discute a loucura também como alteridade e como critério de humanidade, quando por exemplo Radwan pergunta se um louco também é um homem (FARHOUD, 2005, p.184). Embora a loucura seja uma questão central deste romance e igualmente importante para a discussão da produção de malhas afetivas, o foco de análise no escopo deste estudo deve recair sobre o nexo entre afetividade e alteridade, criado a partir de diferenças culturais.

\section{Sentir a diferença}

Como mencionado, o romance de Abla Farhoud é narrado a partir de diferentes perspectivas, majoritariamente por membros da família libanesa, mas também por um 
vizinho socializado no Canadá. Essas perspectivas contribuem para representar uma atmosfera afetiva, a partir da qual a vozes de atores sociais oriundos de fluxos migratórios começam a tomar forma. A passagem a seguir, é narrada do ponto de vista de Radwan, filho de pais libaneses que escolheram o Quebec como destino de seu assentamento:

Durante anos, a gente se sentia como extraterrestres, isso acabou fazendo parte da gente. Nós integramos completamente a espécie de vergonha e mal-estar de ser o que somos. No lugar de se integrar, ao menos de se adaptar a nossa nova vida, a gente integrou o sentido de nunca estar no lugar certo, no momento certo. Os oito membros da nossa família estavam aglutinados, sem mesmo saber que esse cimento que nos mantinha colados uns aos outros era o sentimento de estarmos sempre deslocados. Nunca falávamos disso entre a gente. Essas coisas se sentem, em não se dizem. Cada uma de nós fazia o melhor que podia (FARHOUD, 2005, p. 36) ${ }^{7}$.

No presente diegético, Radwan é confrontado com a morte do pai e, num esforço de rememoração, ele recupera experiências que marcaram os primeiros anos, após a chegada da família no Quebec. A configuração afetiva que impera nesse contexto é a sensação de alteridade como elemento central nas interações do cotidiano. Radwan utiliza a palavra "extraterrestre" para captar essa dinâmica afetiva específica, indicando uma formatação de grupos, na qual eles como estrangeiros não se sentem pertencentes. Antes de ser uma configuração discursiva, o binarismo da formatação nós-eles surge como realidade afetiva que demanda do sujeito um trabalho de processamento e ordenação, para que possa ser simbolizada e posteriormente questionada.

O trabalho de rememoração empreendido por Radwan parece indicar que, na primeira fase de sua permanência no novo país, esse excesso de informação afetiva não passa por uma canalização discursiva, para fazer frente às dinâmicas de exclusão. Pelo contrário, no lugar de refrear as incursões do silenciamento, ocorre a internalização da diferença. Nesse movimento, contudo, o protagonista não internaliza somente as interpretações vigentes sobre a natureza da diferença diante da narrativas dominantes naquele espaço social. Antes de assimilar essas malhas culturais sobre normas e desvio existentes na macrotessitura cultural, ele adquire modos de sentir e de administrar conteúdos afetivos, com base nas dinâmicas socioculturais que predominam nas interações daquelas coordenadas. Portanto, ao integrar a sensação 
de vergonha e mal-estar, ele integra interpretações e visões de mundo daquilo que é considerado apropriado localmente.

A estratégia para lidar com a imposição da diferença também ocorre por meio de dinâmicas afetivas. Há um estreitamento no cerne da família migrante, intensificando o investimento afetivo e o esforço de proteção, a fim de amenizar as investidas do grupo dominante. O esforço de condensação dessa energia afetiva, contudo, tem sua origem justamente na sensação de alteridade e de não pertencimento, causada pelos círculos exteriores à família. Com a finalidade de aplacar essa negação de pertencimento e suprir uma ausência que surge a partir da recusa por parte dos integrantes da comunidade dominante de fornecer interações afetivamente inclusivas, a família se transforma em estrutura indispensável para suprir afetos positivos.

As causas desse estreitamento afetivo como medida de proteção, contudo, não é matéria de discussão entre os membros da família. Alteridade e exclusão perpassam a malha afetiva que circula como energia coesiva nesse microcírculo social, mas não são é alvo de simbolização. Isto é, há uma base afetiva arraigada no princípio da diferença e do deslocamento, partilhada por todos, mas não ocorre um trabalho de organização discursiva desse fenômeno afetivo, de modo que todos o experimentam como coloração emocional, mas sem articular seu impacto em suas percepções de mundo ou sem suas chances de participação e construção de identidade. Com isso, a transmissão de experiências e das vozes que constituem o horizonte de uma comunidade cultural é interrompida nesse primeiro círculo. Essa interrupção parece ocorrer por conta das barreiras de dor, as quais impedem a articulação e a mobilização discursiva.

Essa dinâmica social de formação de laços afetivos, com suas lógicas de agrupamento, despertam o interesse de Radwan. Em seu trabalho de rememoração, ele recupera como a família assume um papel central diante da experiência de exclusão, mas também vai além para refletir sobre outras formas de organização social:

Aqueles que nasceram aqui podem mais facilmente fazer amizade, eles não têm necessidade de se agarrar à família deles. Quando se nasce em outro lugar, a gente se junta com aqueles que nasceram em outro lugar. Ou então com exilados em seu próprio país tão mal aceitos como os verdadeiros. Meus amigos são italianos, 
chilenos, turcos, armênios e algumas lascas soltas da cepa deles (FARHOUD, 2005, p. 51) ${ }^{8}$.

Assim, ele volta seu interesse para o fenômeno da amizade como enfeixamento social que promete pertencimento, identificando que as dinâmicas que regem essa forma de interação de acordo com o capital social. Ao diferenciar os potenciais entre nativos e estrangeiros, ele não remete à diferença cultural, mas sim a um histórico afetivo que contém habilidades para a concretização de mobilidade social. As experiências de fluxos migratórios, com seu processo de reassentamento, exigem um investimento emocial de grandes proporções, especialmente também por conta das não raras vivências de exclusão, transformando a família numa fonte ainda mais importante de fornecimento de afetos positivos. Os nativos, por sua vez, partem de outra realidade, ao fazem suas primeiras incursões em círculos sociais, fora dos círculo familiar. O fato de já possuírem o conhecimento cultural que define modos de comunicação, pensamento, comportamento ou ação (HANSEN, 2003) facilita a construção de novos laços sociais e lhes permite investir sua atenção afetiva em outras áreas ou interações sociais que não seja a família. Com isso, a circulação não só social, mas também de ideias é intensificada.

A estratégia adotada por membros oriundos de contextos de fluxos migratórios, ao menos na percepção dessa voz narrativa, acaba recaindo sobre a identificação de atores sociais com experiências semelhantes, isto é, com conhecimentos afetivos similares e que permitem vislumbrar os conflitos vivenciados naquele contexto social. Também aqui, antes da elaboração discursiva de uma voz comum, ocorre um processo de coesão social por meio de vetores afetivos que definem objetivos comuns. Assim, a base para a construção de um ambiente de proteção e de sensação de pertencimento reside na imaginação de um horizonte afetivo, que compartilha experiências comuns.

\section{Dinâmicas macrossociais}

A sensação de diferença se estabelece na família e nas relações mais próximas, mas também se concretiza em interações mais extensas, em círculos sociais menos propensos à proteção. Também neste contexto, surge uma série de dinâmicas sociais que vão definindo uma atmosfera afetiva que forma a base emocional da diferença e da 
posterior identidade discursiva que vai se delineando como resultado desse conjunto de interações. Uma dessas experiências Radwan recupera do período em que frequentava a escola e interagia com essa instuição, rememorando o papel de destaque assumido pelo irmão nessa experiência de extrema angústia:

Ele me defendia. Ele era o mais forte, embora mais jovem. O que eu teria feito sem ele, nos dias da batalha? Árabes contra não árabes. Sobretudo no famigerado dia em que o diretor queria meter a culpa na gente, os muçulmanos, e em que ele queria nos suspender por uma semana ou mais. Meu irmão Rawi Omar Abou Lkhouloud, que por conta das necessidades de sua carreira se tornou Pierre Luc Duranceau, disse: nós não sairemos daqui. Eu tremia de medo. Eu sempre tremi (FARHOUD, 2005, p. 70-71) ${ }^{9}$.

Diferentemente de Radwan, seu irmão detém um capital afetivo que lhe permite enfrentar as tentativas de silenciamento e exclusão vindas do diretor da escola onde estudam, sem perder seu equilíbrio emocional. Essa resiliência, que surge a partir de uma habilidade de organização afetiva complexa, dá início ao exercício da voz, interrompendo processos automáticos de transmissão e tentativas de imposição de ausência. Esse conhecimento afetivo também vai gerar um conhecimento sobre as lógicas discursivas e sobre as chances de participação na produção de malhas simbólicas naquele espaço. Ao mudar seu nome de Rawi Omar Abou Lkhouloud para Pierre Luc Duranceau, ele não adota somente um nome pronunciável no grupo majoritário daquele contexto cultural, ele também antecipa a mudança no processo de recepção e discussão de suas contribuições.

Com base nas experiências vivenciadas na primeira infância, o irmão se dá conta de que também o processo de recepção é fruto de uma disposição afetiva. Não há transmissão, tampouco presença, sem que haja uma comunidade que esteja disposta a dialogar com aquilo que o indivíduo tem a dizer. A experiência com o diretor da escola lhe ensina que a construção de voz e o investimento afetivo de interlocutores também dependem do agrupamento a que se pertence. Assim, há grupos cujas vozes têm chances de articulação, não pelo conteúdo, mas sim por pertencer a uma determinada categoria que goza da preferência (afetiva) da comunidade majoritária. Com base nesse conhecimento, o irmão acaba mudando seu nome, a fim de obter chances de transmissão daquilo que tem a dizer. Essa mudança ocorre num momento avançado do seu percurso biográfico, como 
resultado de um acúmulo de experiências afetivas feitas ao longo de sua socialização naquela comunidade cultural. Ou seja, ele reconhece que a manutenção do nome árabe vai inseri-lo num contexto de produção discursiva que possivelmente pode reduzir o potencial de recepção.

Outra dimensão desse contexto reside na própria administração afetiva. Embora ela tenha a resiliência necessária para administrar as constantes imposições da diferença, ele também reconhece que isso exige um esforço físico-emocional de propoções substanciais. Isto é, a canalização de afetos acaba sendo direcionada para negociar a participação ou evitar a exclusão, enquanto outros atores sociais investem essa mesma energia em trabalho artístico intelectual. Esse conhecimento só reforça sua inteligência emocional, pois ele comprende uma dimensão importante da lógica afetiva, ao identificar que esta é limitada e pode ser consumida exclusivamente para repelir as tentativas de silenciamento. No lugar de investir seus afetos exclusivamente na negação da alteridade imposta, ele se apropria das lógicas discursivas e opta pelo caminho de menor dificuldade.

Radwan não deixa de criticar esse comportamento, especialmente porque contém um movimento de negação da origem. Isto é, no lugar de afirmar sua diferença e lutar por sua presença no grupo dominante, ele a oblitera, esquivando-se com isso de um importante trabalho de representação. $\mathrm{O}$ irmão reconhece a pertinência dessas críticas, mas ele também reconhece a lógica individual de sua configuração afetiva. Ao optar por esse caminho, ele nega a representação da diferença, mas participa da produção discursiva. Esse é o modo como ele administra seus afetos. Ao contrário dele que encontra uma solução pessoal, Radwan continua tomado pelo medo que caracteriza a interação com o diretor na passagem citada. Ao longo do romance, ele também indica a dificuldade que encontra em escrever, portanto, de se articular e participar do coro de vozes que configuram sua sociedade. Essa dificuldade reside, antes de mais nada, na disposição afetiva que o impede de processar as inúmeras tentativas de silenciamento e de negação de pertencimentos aos diferentes agrupamentos.

Uma última dimensão importante nessa passagem é a formação de grupos: árabes e não árabes, muçulmanos e não muçulmanos. O momento da narração difere no momento da experiência narrada. Isto é, Radwan relata os acontecimentos num 
processo de rememoração do passado, organizando e interpretando os eventos a partir da perspectiva avantajada da voz adulta. Ao contrário desse momento de concretização existencial e intelectual que permite a identificação de lógicas comportamentais naquele espaço social, a experiência no período escolar é vivenciada por um sujeito que ainda não tem muito conhecimento sobre as regras de inclusão e exclusão. Na retrospectiva, é possível identificar a construção binária de grupos, a qual polariza e exclui. No momento da interação recuperada do passado, impera uma dinâmica afetiva que indica à criança que ela não pode contar com a simpatia ou com qualquer outro investimento afetivo estimulador de coesão social.

Essa dinâmica discutida no contexto institucional da escola volta em outras situações, mostrando a labilidade e arbitrariedade no que concerne ao investimento afetivo. Assim, Radwan cria um nexo de semelhança com um episódio, envolvendo um atleta jamaicano: "Isso me lembra da história do velocista que chamavam de grande canadense quando estava ganhando a medalha de ouro nos Jogos Olímpicos e, assim que foi pego em flagrante pelo delito de consumo de esteróides, voltou a ser jamaicano" $\left(\right.$ FARHOUD, 2005, p. 71) ${ }^{10}$. Nesse exemplo, o estrangeiro é depositário de energia afetiva positiva, em forma de admiração pelos méritos esportivos, mas sobretudo em forma de acolhimento como membro da comunidade que forma o grupo nacional. Enquanto ele contribui para potencialização de uma imagem nacional positiva, esse investimento permanece ininterrupto. Assim que ele a macula, ao cometer um crime, ocorre a interrupção imediata não só da admiração, para sobretudo do pertencimento à narrativa nacional.

Com isso, a Radwan traça paralelos de semelhança no plano interpessoal do contexto da escola, no plano nacional por meio de exemplo do desportista jamaicano e se repete mais uma vez no plano internacional, exemplicado com a percepção de árabes por americanos. Desta vez, o relato ocorre a partir da perspectiva do irmão Pierre Luc Duranceau, que acaba por se estabelecer nos Estados Unidos, onde constrói sua carreira de escritor. Por um lado, esse afastamento está relacionado aos conflitos e problemas da família, ao mesmo tempo, contudo, representa uma forma de fuga das lógicas rígidas de pertencimento que encontra no Quebec. 
Contudo, também nesse novo contexto, ele encontra dinâmicas afetivas não muito diferentes daquelas vivenciadas no Canadá: "Depois do 11 de setembro de 2001, meu medo se multiplicou por dez. Se os americanos se esforçavam em ser amáveis comigo, querendo repentinamente saber quem eu era... Eles passam o pente fino em tudo. Perfil racial, prática antiga que voltou à moda; os negros estão acostumados a isso, agora é a vez dos árabes, dos muçulmanos. Todos potencialmente terroristas... Paranóia. Islamofobia” (FARHOUD, 2005, p. 123). ${ }^{11}$ A despeito da mudança de nome e da localização geográfica, o irmão continua confrontado com imposições da diferença, agora com foco no pertencimento étnico. Como nas outras situações, a base dessa experiência reside em dinâmicas afetivas, neste caso marcadas pelo medo. O que diferencia essa situação do contexto escolar ainda no Canadá é a capacidade de avaliação e de nomeação das lógicas de exclusão. Neste caso, o irmão identifica claramente os movimentos empreendidos para criar binarismos e também consegue traçar paralelos históricos com outros grupos excluídos. Em ambos os contextos, a presença de dimensões afetivas antecede qualquer negociação e articulação.

\section{Considerações finais}

O romance de Abla Farhoud representa uma importante contribuição para a literatura dos fluxos migratórios. O texto se junta a outras produções literárias artísticas que buscam preencher uma ausência e dar voz a um novo grupo de atores sociais que circulam na sociedade canadense. Ao encenar a voz imigrante, há um esforço de recuperar memórias e experiências socioculturais, a fim de transmiti-las a partir do discurso ficcional. O que caracteriza o texto é a presença ininterrupta de malhas afetivas que formam a base para qualquer interação na esfera ficcional. São essas malhas afetivas que definem o modo como essas personagens processam visões binaristas e reagem contra a imposição de diferença.

Com isso o romance contém um movimento de imaginação de comunidades, segundo Anderson, incluindo nele a presença de membros oriundos dos fluxos migratórios. Nesse movimento, o universo ficcional mostra que antes do estabelecimento da narrativa nacional, incluindo as ramificações discursivas como os "estrangeiros de 
dentro" ou a "poética da escrita migrante", ocorre uma dinâmica emocional em que os mais diversos afetos são processados e negociados. É a partir dessa base afetiva que surge o desejo de organização de uma voz para preencher as ausências discursivas e para resistir à negação de pertencimento.

\section{Referências}

ANDERSON, Benedict. Comunidades imaginadas. Reflexões sobre a origem e a difusão do nacionalismo. Tradução: Denise Bottman. São Paulo: Companhia das Letras, 2008.

BENNETT, Donna. Getting Beyond Binaries: Polybridity in Contemporary Canadian Literature. In: KANAGANAYAKAM, Chelva (ed.). Moveable Margins: the shifting spaces of Canadian Literature. Toronto: Tsar Publications, 2005, p. 9-25.

BERND, Zilá. Redéfinir l’identité canadienne en termes de communautés de mémoire. In: Études canadiennes / Canadian Studies, v. 83, p. 133-145.

DUMONTET, Danielle. Pour une poétique de l'écriture migrante. L'exemple du Québec. In: DUMONTET, Danielle; ZIPFEL, Frank (eds.). Écriture Migrante/Migrant Writing. Hildesheim: Georg Olms Verlag, 2008, p. 87-108.

FARHOUD, Abla. Le fou d'Omar. Montreal: VLB éditeur, 2005.

FRIJDA, N. H. The Emotions.Cambridge: University Press, 1987.

HANSEN, Klaus P. Kultur und Kulturwissenschaften. Tübingen e Basel: A. Francke Verlag, 2003.

HAREL, Simon. Les passages obligés de l'écriture migrante. Montreal: XYZ éditeur, 2005.

MOISAN, Clément; HILDEBRAND, Renate. Ces étrangers du dedans. Une histoire de l'écriture migrante au Québec (1937-1997). Montréal: Nota bene, 2001.

OUELLET, Pierre. Testaments. Le témoignage et le sacré. Montréal: Liber, 2012.

TURNER, Jonathan H.; STETS, Jan E. The Sociology of Emotions. Cambridge: University Press, 2005.

\section{Notes}

1 Professor do Departamento de Letras Estrangeiras Modernas e do Programa de Pós-Graduação em Letras da Universidade Federal de Santa Maria. Contato: dioneimathias@gmail.com

2 "Parmi les aspects que nous semblent constitutifs d'une poétique de l'écriture migrante, nous en retiendrons quatre qui sont d'une part la déterritorialisation de la parole migrante, d'autre part la resémantisation de l'espace et encore l'écriture en plusieurs langues et enfin l'écriture en fragments“ (DUMONTET, 2008, p. 93).

3 "the literature of our cultures offers us other ways of seeing" (BENNETT, 2005, p. 12).

4 "Ils ne tombent pas dans le piège de la pensée binaire qui implique nécessairement des exclusions, dans la mesure où le binarisme empêche la perception d'une troisième voie" (BERND, 2017, p. 135).

5 "tendencies to establish, maintain, or disrupt a relationship with the environment" (FRIJDA, 1987, p. 71). 
6 "For most sociologists, emotions are socially constructed in the sense that what people feel is conditioned by socialization into culture and by participation in social structures. Cultural ideologies, beliefs, and norms as they impinge on social structures define what emotions are to be experienced and how these culturally defined emotions are to be expressed. Emotions are thus social constructions" (TURNER/ STETS, 2005, p. 2).

7 "Pendant des années, on s'est sentis des extraterrestres, ça a fini par faire partie de nous. On a complètement intégré l'espèce de honte et malaise d'être ce qu'on est. Au lieu de s'intégrer, au moins de s'adapter à notre nouvelle vie, on a intégré le sentiment d'être jamais à la bonne place au bon moment. Les huit membres de notre famille étaient agglutinés, sans même savoir que ce ciment qui nous gardait collés les uns aux autres était le sentiment d'être toujours à côté de la plaque. Jamais on n'en parlait entre nous. Ces choses-là se sentent et ne se disent pas. Chacun de nous faisait du mieux qu'il pouvait" (FARHOUD, 2005, p. 36).

8 "Ceux qui sont nés ici peuvent plus facilement se faire des amis, ils n'ont pas besoin de s'accrocher à leur famille. Quand on est né ailleurs, on se ramasse avec ceux qui sont nés ailleurs. Ou bien avec des exilés dans leur propre pays aussi mal pris que les vrais. Mes amis sont italiens, chiliens, turcs, arméniens et quelques copeaux détachés de leur souche" (FARHOUD, 2005, p. 51).

9 "Il me défendait. Il était le plus fort même si plus jeune. Qu'est-ce que j'aurais fait sans lui, les jours de bataille? Arabes contre non-Arabes. Surtout le fameux jour où le directeur voulait mettre la faute sur nous, les musulmans, et qu'il voulait nous suspendre pour une semaine ou plus. Mon frère Rawi Omar Abou Lkhouloud, devenu pour les besoins de sa carrière Pierre Luc Duranceau, a dit : nous ne sortirons pas d'ici. Moi je tremblais de peur. J'ai toujours tremblé" (FARHOUD, 2005, p. 70-71).

10 "Ça me rappelle l'histoire du sprinter qu'on appelait un grand Canadien quand il était en train de gagner la médaille d'or des Jeux olympiques et aussitôt qu'on l'a pris en flagrant délit de consommation de stéroïdes, il était redevenu un Jamaïcain" (FARHOUD, 2005, p. 71).

11 "Depuis le 11 septembre 2001, ma peur a décuplé. Si les Américains se mettaient en frais d'amabilité pour moi en voulant soudainement savoir qui je suis...Ils passent tout au peigne fin. Profilage racial, ancienne pratique remise à la mode; les Noirs y sont habitués, c'est maintenant au tour des Arabes, des musulmans. Tous potentiellement terroristes...Paranoïa. Islamophobie" (FARHOUD, 2005, p. 123). 